Delft University of Technology

\title{
Barriers and Drivers of Digital Transformation in Public Organizations Results from a Survey in the Netherlands
}

Tangi, Luca; Janssen, Marijn; Benedetti, Michele; Noci, Giuliano

DOI

10.1007/978-3-030-57599-1_4

Publication date

2020

Document Version

Final published version

Published in

Electronic Government - 19th IFIP WG 8.5 International Conference, EGOV 2020, Proceedings

\section{Citation (APA)}

Tangi, L., Janssen, M., Benedetti, M., \& Noci, G. (2020). Barriers and Drivers of Digital Transformation in Public Organizations: Results from a Survey in the Netherlands. In G. Viale Pereira, M. Janssen, H. Lee, I. Lindgren, M. P. Rodríguez Bolívar, H. J. Scholl, \& A. Zuiderwijk (Eds.), Electronic Government - 19th IFIP WG 8.5 International Conference, EGOV 2020, Proceedings (pp. 42-56). (Lecture Notes in Computer Science (including subseries Lecture Notes in Artificial Intelligence and Lecture Notes in Bioinformatics); Vol. 12219 LNCS). Springer Science+Business Media. https://doi.org/10.1007/978-3-030-57599-1_4

\section{Important note}

To cite this publication, please use the final published version (if applicable).

Please check the document version above.

\section{Copyright}

Other than for strictly personal use, it is not permitted to download, forward or distribute the text or part of it, without the consent of the author(s) and/or copyright holder(s), unless the work is under an open content license such as Creative Commons.

Takedown policy

Please contact us and provide details if you believe this document breaches copyrights.

We will remove access to the work immediately and investigate your claim. 
Green Open Access added to TU Delft Institutional Repository

'You share, we take care!' - Taverne project

https://www.openaccess.nl/en/you-share-we-take-care

Otherwise as indicated in the copyright section: the publisher is the copyright holder of this work and the author uses the Dutch legislation to make this work public. 


\title{
Barriers and Drivers of Digital Transformation in Public Organizations: Results from a Survey in the Netherlands
}

\author{
Luca Tangi $^{1(\otimes)}(\mathbb{D})$, Marijn Janssen $^{2}$ (D), Michele Benedetti ${ }^{1}$ (D), and Giuliano Noci ${ }^{1}$ \\ ${ }^{1}$ Department of Management, Economics, and Industrial Engineering, Politecnico di Milano, \\ Milan, Italy \\ \{luca.tangi, michele.benedetti,giuliano.noci\}@polimi.it \\ 2 Faculty of Technology, Policy and Management, Delft University of Technology, Delft, \\ The Netherlands \\ m.f.w.h.a.janssen@tudelft.nl
}

\begin{abstract}
The introduction of ICT is requiring public administrations to transform their organizations to take advantage of these technologies. Despite its significance, no studies so far collected quantitative evidence on (i) how and the extent to which this transformation is currently underway and (ii) which drivers and barriers are hindering and leading this transformation process. This article aims at filling this gap by surveying Dutch public administrations. In total, 46 responses from different organizations were collected that provide insight into their transformation efforts. Findings show that digital transformation efforts had only a partial impact at the organizational level: processes, employees' duties and tasks and information systems are going through a deep transformation, whereas the social system seems to be less affected by the transformation process. Moreover, the analysis results suggest that external drivers are the main motivation for organizational transformation, and that expected internal barriers do not de facto result in digital transformation. These counterintuitive results suggest that in public administrations only exogenous input result in a sense of urgency and that the perceived barriers to transformation can be overcome if there is sufficient external pressure.
\end{abstract}

Keywords: Organizational transformation - Transformational government . Socio-technical theory $\cdot$ Barriers and drivers $\cdot$ E-government

\section{Introduction}

New digital technologies promise a more efficient public administration as well as a more effective service provision $[1,2]$. However, the achievement of this promise gets often stuck on embedded norms, bureaucracy, processes, and structure [3]. The linkage between the introduction of ICT and the organizational transformation process is unavoidable: the pervasiveness of ICT in public affairs is forcing public agencies not to reduce the introduction of ICT to a mere dematerialization, i.e. substituting a physical 
means with digital ones, rather to pursue a necessary (and complex) process of organizational revision for letting the new digital technologies be institutionalized and routinized $[4,5]$. Newer technologies should mean newer management, newer competences, newer organizational and inter-organizational structures [6] and often they require a radical change, asking for a disruption of the status quo and the standard operating procedures, by experimenting and iterating with technologies that are not part of the standard toolkit of public administrations [7]. The latter is often referred as transformation. Transformation entails a change in the whole organization, i.e. processes, employees' duties and tasks, information systems, organizational culture and behaviors, and the hierarchical structure. ICT has the potential to impact all those elements [3]. However, so far, the if, how and under which conditions the transformation took place is still unclear.

Some studies explore transformational efforts being undertaken by governments on all levels [8-10], while others highlight a lack of empirical evidence that real public sector transformation has taken place [11]. Moreover, all studies conducted so far are based on case studies, leaving a lack of understanding on the depth and the widespread of this ongoing transformation in the public sector. The cases often show that there are many impediments that complicate transformation as well as many drivers that foster it. Literature deeply investigates barriers and drivers, and categorizes them in different ways (see for example [12, 13]). This literature suggests that these elements have an influence on transformation. However, despite such literature deploying consolidated claims, there is a lack of research that quantitatively test the extent to which they influence the transformation. A quantitative analysis will cast light on the topic exploring if and which of the barriers, drivers and transformation processes observed with case studies can be reliable on a large scale.

This article aims to understand the depth of technology-driven public sector transformation and if and the extent to which barriers and drivers condition this transformation. For this, we review the literature and develop a conceptual model. This model is used to conduct a survey. Finally, conclusions are drawn.

\section{Literature Review and Conceptual Model}

Previous researches stated that organizational transformation is a necessary condition to realize ICT potential, as well as one of the main challenges public administrations are facing nowadays $[3,9]$. On the other side, scholars so far identified several barriers and drivers that can foster or hinder this transformation process. However, only a few attempts have been made to construct and test a model that can explain this transformation [9]. Therefore, we define a model (Fig. 1) that on the one hand aims at assessing the level of ICT-embedded transformation (dependent variables) and, on the other hand the drivers and barriers that can enable or block it (independent variables). In doing that, we rely on the existing literature for grounding on a solid theoretical background each element that feed the design of the overall model and the hypotheses statement. 


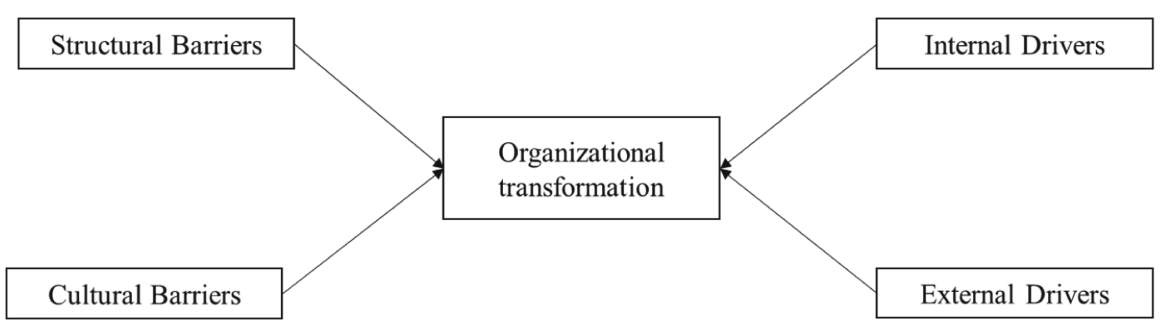

Fig. 1. Framework of analysis

\subsection{Organizational Transformation}

Organizations are complex systems that can be considered as the ensemble of five different elements: process, people, culture, structure and information system [3, 9]. Scholars unanimously agree that those elements are interdependent, therefore a change in one of them can cause changes in the others [3, 14, 15]. The five elements are described in Table 1. The Table provides also a list of examples on the impacts of ICT for each element.

According to the socio-technical theory those five elements can be grouped into two independent but interactive macro-systems that compose the organization [14]:

- the technical system, composed by those elements necessary to transform input into output (process, tasks, duties, information system).

- the social system that is concerned with all those elements that are related to the environment the technical system in embedded in, the organizational culture and values, and the authority structure.

The introduction of ICT has a direct effect on the technical system. However, previous studies demonstrate that the success of technology implementation is fastly tightened to a change also in the social system [3]. In fact, when organizations design a project that pursues a change only in the technical system, they are more likely to encounter failure [14].

Therefore, the introduction of ICT in an organization is supposed to have an impact on the organization as a whole [3]. Hence, we collect evidence taking into consideration all the five elements that characterize it, without assuming any ex-ante hypothesis about the type of relation between them $[3,10,15,16]$. Thus, we state the following proposition (we do not articulate it as a hypothesis due to the absence of a quantitative method to test it):

P1. Transformation results in changes in the whole organization, impacting all the five elements that ensemble it.

When discussing organizational change, the first variable necessary to consider is the organization size. We intuitively expect that, as for other types of organizational change, bigger organizations are less flexible and more bureaucratic and therefore the transformation process is more complex and organizations are subject to minor changes. 
Table 1. Elements of organizational transformation

\begin{tabular}{l|l|l}
\hline Element & Description & Literature examples \\
\hline Process & $\begin{array}{l}\text { The set of activities to transform an input in output } \\
\text { and to manage and control the entire process }\end{array}$ & {$[3,15,16]$} \\
\hline People & $\begin{array}{l}\text { Employees' duties and tasks and, therefore, in the } \\
\text { competences needed }\end{array}$ & {$[3,15]$} \\
\hline Culture & $\begin{array}{l}\text { Endorsed values and personal and collective } \\
\text { behaviors }\end{array}$ & {$[3,15,16]$} \\
\hline Structure & $\begin{array}{l}\text { The organizational structure, i.e. the level of } \\
\text { centralization/decentralization of responsibilities, } \\
\text { the hierarchical structure and the degrees of } \\
\text { flexibility }\end{array}$ & {$[3,15]$} \\
\hline Information system & $\begin{array}{l}\text { The technological systems employed for } \\
\text { managing the activities, i.e. all the software, } \\
\text { hardware and the integration between them }\end{array}$ & {$[15]$} \\
\hline
\end{tabular}

H1. The size of the organization negatively influences the level of organizational transformation.

\subsection{Barriers and Drivers}

When approaching a complex process of organizational transformation led by new digital technologies, several barriers can come about and hinder the change [13]. Based on literature, barriers are divided into two categories: structural barriers and cultural barriers. Structural barriers comprehend organizational and managerial factors intrinsic to the characteristics of the organization, whereas cultural barriers comprehend behaviors of the employees that can hinder the change. Table 2 resumes the identified barriers.

As stated by previous studies, the listed barriers block or hinder the transformation process $[13,15]$. In order verify those statements on a large scale, we formulate the following hypotheses.

H2. Structural barriers negatively influence the depth of ICT-embedded organizational transformation

H3. Cultural barriers negatively influence the depth of ICT-embedded organizational transformation

On the other side, literature identifies also several factors that encourage change. We divided the drivers into two categories: internal and external. On the one hand, internal drivers analyze the presence in the organization of elements (like a charismatic leader or some inefficiencies) that make the change more urgent. On the other hand, the urgency of change can come also from outside the organization (external drivers) for example from the pressure of external stakeholder or legal obligations. Table 3 summarizes the identified drivers. 
Table 2. Barriers to ICT-embedded organizational transformation

\begin{tabular}{l|l|l}
\hline Category & Barrier & Literature examples \\
\hline \multirow{3}{*}{ Structural barriers } & Lack of managerial support & {$[4,17,18]$} \\
\cline { 2 - 3 } & Lack of political support & {$[4,17,18]$} \\
\cline { 2 - 3 } & Lack of available skills & {$[12,19,20]$} \\
\cline { 2 - 3 } & Shortage of personnel & {$[12,19,20]$} \\
\cline { 2 - 3 } & Organizational complexity & {$[13,21]$} \\
\cline { 2 - 3 } $\begin{array}{l}\text { Cultural } \\
\text { barriers }\end{array}$ & $\begin{array}{l}\text { Lack of coordination among the departments/areas of } \\
\text { the organization }\end{array}$ & {$[16,19,22]$} \\
\hline & Resistance to change & {$[15,16]$} \\
\cline { 2 - 3 } & Bureaucratic culture & {$[13,23]$} \\
\cline { 2 - 3 } & Fear of innovation & {$[23]$} \\
\hline
\end{tabular}

Table 3. Drivers to ICT-embedded organizational transformation

\begin{tabular}{l|l|l}
\hline Category & Barrier & Literature examples \\
\hline \multirow{2}{*}{ Internal drivers } & Strength of internal leadership & {$[3,24]$} \\
\cline { 2 - 3 } & Internal dissatisfaction about the status quo & {$[8,12]$} \\
\cline { 2 - 3 } & Expected benefits for the administration & {$[20]$} \\
\hline \multirow{2}{*}{ External drivers } & $\begin{array}{l}\text { Expected benefits for external actors (stakeholders } \\
\text { and/or final users) }\end{array}$ & {$[23]$} \\
\cline { 2 - 3 } & External pressure & {$[9,25]$} \\
\cline { 2 - 3 } & External legal obligations & {$[9]$} \\
\hline
\end{tabular}

Following the same logic adopted for the barriers, we formulate the following hypotheses.

H4. Internal drivers positively influence the depth of ICT-embedded organizational transformation

H5. External drivers positively influence the depth of ICT-embedded organizational transformation

\section{Research Approach}

\subsection{Survey Design}

For testing the hypotheses, a questionnaire was developed and delivered to Dutch public managers. Barriers, drivers and the transformation process are intangible factors, therefore can be assessed only directly asking them to public managers. 
The questionnaire was designed following the model presented in Fig. 1. The questionnaire had two sections to make it easier for reading and completing. Section A includes the questions related to the conceptual model. Three questions were defined (in Appendix I the questionnaire):

- questions 1 aims at measuring the dependent variable, i.e. the depth of organizational transformation (process, people, culture, structure, information system). For each element the level of agreement on the impact of ICT was questioned with a 5-point Likert scale.

- question 2 measures the barriers. For each barrier the level of agreement on how this barrier hinders the transformation process that goes along with the introduction of ICT was questioned with a 5-point Likert scale.

- question 3 measures the drivers. For each driver the level of agreement on how this driver pushes the transformation process that goes along with the introduction of ICT was questioned with a 5-point Likert scale.

In section A the respondents were clearly asked to consider the characteristics and the changes in the whole organization over the past couple of years.

Section B asked for demographic information in the form of multiple-choice questions. The section investigates the characteristics of the organization, such as type of administration, number of employees.

The survey was circulated by the Dutch association of municipalities (VNG) and the innovation vehicle of the Dutch government (deDigiCampus.nl). Before sending the survey, a pilot test with a first round of interviews involving 4 public managers was conducted for verifying the intelligibility and the completeness of the questionnaire. After that, the questionnaire was revised and a second pilot test was run with the Dutch association of municipalities for ensuring the goodness of the changes.

The survey was conducted between January and March 2020. At the beginning of February, a recall was made to increase the number of respondents.

The Netherlands were selected for this study due to their high level of e-government maturity and the variety in approaches taken as a decentralized unitary state. This country is enumerated among the "fruitful eGovernment" countries with a high level of digitization and ICT penetration [26]. The Netherlands is the constituent country of the Kingdom of Netherlands, which has also island territories located in the Caribbean. The major political institutions in the country are the monarchy, the parliament, the judiciary and the cabinet. Other levels of government include the municipalities, the provinces, and the water-board. These have their own elected council. Each of them decide on adopting their own technology. The municipalities collaborate in the association of municipalities to focus their efforts and share experiences. Nevertheless, each municipality can choose their own approach to digital transformation. Thanks to the stable relation of the authors with VNG and the deDigiCampus we had the opportunity to have a preferential communication channel for obtaining a large number of responses by public managers. 


\subsection{Sample and Methods}

In total 48 responses were collected, 2 of them were discarded due to incompleteness. Table 4 shows the characteristics of the sample. Firstly, some descriptive statistics were analyzed. Before testing the hypothesis, looking at all the items singularly allows the collection of some more qualitative insight for discussing P1 and identify the more relevant barriers and drivers. Next, a t-test was run for testing H1. Simple regression was run in order to test the hypotheses from 2 to 4.

Table 4. Descriptive statistics of the sample

\begin{tabular}{|c|c|c|c|}
\hline Element & Mean & Frequency & Percent \\
\hline \multirow[t]{2}{*}{ Size } & $<2000$ employees & 29 & 63,0 \\
\hline & >2000 employees & 17 & 37,0 \\
\hline \multirow[t]{6}{*}{ Type of administration } & Administrative organization & 8 & 17,4 \\
\hline & Ministry & 4 & 8,7 \\
\hline & Municipality & 27 & 58,7 \\
\hline & Other & 1 & 2,2 \\
\hline & Other government & 4 & 8,7 \\
\hline & Regional administration & 2 & 4,3 \\
\hline \multirow[t]{4}{*}{ Role } & Director & 5 & 10,9 \\
\hline & Other & 9 & 19,6 \\
\hline & Public manager & 13 & 28,3 \\
\hline & Public servant & 19 & 41,3 \\
\hline \multirow{2}{*}{$\begin{array}{l}\text { Year of experience in the public } \\
\text { sector }\end{array}$} & $<5$ years & 2 & 4,3 \\
\hline & $\geq 5$ years & 44 & 95,7 \\
\hline \multirow{2}{*}{$\begin{array}{l}\text { Year of experience in the current } \\
\text { administration }\end{array}$} & $<2$ years & 3 & 6,5 \\
\hline & $\geq 2$ years & 43 & 93,5 \\
\hline
\end{tabular}

\section{Results}

\subsection{Organizational Transformation}

Before testing the hypotheses, exploratory analysis was conducted to explain and discuss the extent to which ICT is leading to a transformation. We firstly took into consideration the five elements that characterize an organization (process, people, culture, structure and information system) in order to understand which of the elements are more impacted by the introduction of ICTs. Table 5 shows the results in terms of mean and standard deviation. 
Table 5. ICT-embedded organizational transformation - exploratory results

\begin{tabular}{l|l|l}
\hline Element & Mean & Std. dev. \\
\hline Process & 3,66 & 1,28 \\
\hline People & 3,39 & 1,08 \\
\hline Culture & 2,75 & 0,99 \\
\hline Structure & 2,82 & 1,10 \\
\hline Information system & 3,84 & 1,10 \\
\hline
\end{tabular}

Table 5 offers some quantitative evidence that partially confirms P1: on average, respondents stated that ICTs are transforming the organizations in terms of processes, people and information systems (all the means above 3 out of 5). Moreover, ICTs seems on average less impactful on organizational culture and structure.

The t-test for testing H1 was conducted including only the technical system, i.e. the elements that resulted impacted by the introduction of ICTs (process, people and information system). Those elements were aggregated into an overall indicator summing them together and dividing them by the maximum score achievable (15 out of 15). Appendix II shows the reliability test. The administrations were divided into two categories with respect to their number of employees. Due to the structural characteristics of the Netherlands, the threshold was identified as 2000 employees. The test confirms H1 for both categories. Table 6 and 7 show the results of the test.

Table 6. Organizational transformation and size of the administration - mean and std. dev.

\begin{tabular}{l|l|l|l}
\hline Category & N & Mean & Std. dev. \\
\hline >2000 employees & 29 & 0,7586 & 0,18131 \\
\hline$\leq 2000$ employees & 17 & 0,6353 & 0,20438 \\
\hline
\end{tabular}

Table 7. Organizational transformation and size of the administration - t-test

\begin{tabular}{l|l|l|l|l|l}
\hline & $\begin{array}{l}\text { Levene's test } \\
\text { F }\end{array}$ & $\begin{array}{l}\text { Levene's test } \\
\text { Sig. }\end{array}$ & t & df & Sig. (2-tailed) \\
\hline Equal variances assumed & 0,449 & 0,506 & 2,132 & 44 & $0,039 *$ \\
\hline
\end{tabular}

Note: $* \mathrm{p}<0.05, * * \mathrm{p}<0.01, * * * \mathrm{p}<0.001$

\subsection{Organizational Transformation Barriers and Drivers}

For the correlation test we aggregated structural barriers, cultural barriers, external drivers and internal drivers into the four overall indicators. In this way summing the 
single items together and dividing them by the maximum score achievable. In order to be coherent with the previous analysis the depth of organizational transformation was calculated by taking into consideration only the technical system. However, similar results would have been achieved taking when taking into consideration the social system.

Table 8 shows the descriptive statistics of the sample, Table 9 summarizes the results of the analysis. $\mathrm{H} 2, \mathrm{H} 3$ are rejected, $\mathrm{H} 4$ could not be tested, due to reliability issues of the overall indicator (see Appendix II), and H5 is confirmed.

The results show that the only independent variable having an impact on the depth of organizational transformation is the external drivers (except for the size of the administration). Public administrations that feel the pressure of an organizational transformation from outside are the ones that have recognized the most an organizational transformation led by the introduction of ICT.

Table 8. Barriers and drivers - descriptive statistics

\begin{tabular}{l|l|l|l|l}
\hline & Minimum & Maximum & Mean & $\begin{array}{l}\text { Std. } \\
\text { deviation }\end{array}$ \\
\hline SB_Skills & 2,00 & 5,00 & 3,8261 & 0,87697 \\
\hline SB_Personnel & 1,00 & 5,00 & 3,4348 & 1,00338 \\
\hline SB_PolSupport & 1,00 & 5,00 & 3,5217 & 1,06956 \\
\hline SB_ManagSupport & 1,00 & 5,00 & 3,6087 & 1,14462 \\
\hline SB_Complexity & 1,00 & 5,00 & 4,0000 & 1,07497 \\
\hline SB_Coordination & 2,00 & 5,00 & 4,2391 & 0,84813 \\
\hline SB_TOT & $\mathbf{0 , 4 7}$ & $\mathbf{0 , 9 7}$ & $\mathbf{0 , 7 5 4 3}$ & $\mathbf{0 , 1 2 0 3 6}$ \\
\hline CB_Resistance & 2,00 & 5,00 & 3,6304 & 1,01890 \\
\hline CB_Culture & 2,00 & 5,00 & 3,8696 & 0,95705 \\
\hline CB_Fear & 2,00 & 5,00 & 3,6087 & 0,99952 \\
\hline CB_TOT & $\mathbf{0 , 4 0}$ & $\mathbf{1 , 0 0}$ & $\mathbf{0 , 7 4 0 6}$ & $\mathbf{0 , 1 5 4 1 1}$ \\
\hline ID_Leader & 1,00 & 5,00 & 3,0870 & 1,07137 \\
\hline ID_Dissatisfaction & 1,00 & 5,00 & 2,9565 & 1,11468 \\
\hline ID_IntBenefit & 1,00 & 5,00 & 3,6087 & 0,90623 \\
\hline ID_TOT & $\mathbf{0 , 2 0}$ & $\mathbf{0 , 8 7}$ & $\mathbf{0 , 6 4 3 5}$ & $\mathbf{0 , 1 4 8 8 8}$ \\
\hline ED_ExtBenefit & 1,00 & 5,00 & 3,5870 & 1,02363 \\
\hline ED_Pressure & 1,00 & 5,00 & 3,3913 & 0,99952 \\
\hline ED_Obligation & 1,00 & 5,00 & 3,5217 & 1,13017 \\
\hline ED_TOT & $\mathbf{0 , 2 0}$ & $\mathbf{1 , 0 0}$ & $\mathbf{0 , 7 0 0 0}$ & $\mathbf{0 , 1 6 3 7 5}$ \\
\hline & & & &
\end{tabular}


Table 9. Organizational transformation - regression results

\begin{tabular}{l|l|l|l|r|l}
\hline & \multicolumn{2}{|l|}{\begin{tabular}{l} 
Unstandardized \\
\multicolumn{2}{l}{ coefficients }
\end{tabular}} & Standardized coefficients & t & Sig. \\
\cline { 2 - 5 } & B & Std. error & Beta & & \\
\hline (Constant) & 0,345 & 0,252 & & 1,370 & 0,178 \\
\hline CB_TOT & $-0,174$ & 0,232 & $-0,107$ & $-0,751$ & 0,457 \\
\hline SB_TOT & 0,148 & 0,197 & 0,116 & 0,752 & 0,456 \\
\hline ED_TOT & 0,629 & 0,172 & 0,523 & 3,666 & $0,001^{* * *}$ \\
\hline EMP2 & $-0,135$ & 0,051 & $-0,336$ & $-2,628$ & $0,012^{*}$ \\
\hline
\end{tabular}

Note: $* \mathrm{p}<0.05, * * \mathrm{p}<0.01, * * * \mathrm{p}<0.001$

\section{Discussion}

Firstly, our study quantitative tested and confirmed that the introduction of ICTs is often combined with a transformation of the whole organization (P1). Going deeper into this evidence, the results show that the technical system of an organization (process, people and IS) is the most impacted by the introduction of ICT. On the other side, the social system (culture and structure) is less affected by this transformation.

This evidence corroborates the validity of the socio-technical theory [14] also in a digital setting. The social system is the one with a slower reaction time: change the organizational culture and the entire structure of a public administration it's a longer and more difficult process [27]. We can therefore hypothesize a two-step ICT-embedded organizational transformation: firstly, ICT transforms the technical system of an organization, secondly (temporarily speaking) the social one. The same phenomenon could be explained using the terminology suggested by Mergel et al. [25]: digitalization to define the change that involves a transformation existing processes and forms and digital transformation for emphasizing cultural and organizational change.

Adopting this classification, the results shows that, in the Netherlands, i.e. one of the country with the highest level of e-government digital maturity, public administrations are going through the digitalization process (i.e. a change in the technical system), while the digital transformation one (i.e. a change in the social system) is still in an embryonic phase.

On the other side, the Netherlands are a country where, on average, public administrations have a high level of complexity, due in primis to their large size. The results show, confirming H1, that the size of the administration is correlated with the depth of organizational transformation: for big and complex administrations the transformation process is less clear than in the smaller ones.

The second step includes in the analysis drivers and barriers. Firstly, a descriptive look to the data collected confirm the existing literature on the presence of structural and cultural barriers that curb the transformation (both above 0.7). The size of the Dutch Public Administration can explain why a lack of coordination and organizational complexity 
are the ones with a higher score (respectively 4.2 and 4.0). Instead, between the cultural barriers, bureaucratic culture has been identified as the most relevant impediment to face (3.9).

However, the evidence from the correlation analysis (Table 9) denies that the presence of those barriers has a relation with the depth of organizational transformation, influenced instead only by external drivers (H5). This result is partially in contrast with previous studies: even if public managers recognize the presence of barriers that obstruct the transformation process $[13,15]$, the study demonstrates that the deepness of the transformation is not related with the strength of those barriers. We are aware that this result might be influenced by the limited number of observations and self-selection bias. However, this counterintuitive evidence gives room to some further considerations and hypotheses to explain the obtained results.

External factors have a positive effect on the depth of the transformation. Administrations that feel the pressure (or the obligation) to change are the ones who also declare a higher degree of organizational transformation. This evidence can be explained by the nature of the public sector itself. The absence of the need of and pressure for being profitable or the risk of going bankrupt might make public servants less sensitive for internal pressures, whereas a request from the outside the administration is viewed as urgent. A direct consequence of that is the deployment of ICT as an instrument for improving services and participation, requests that come directly from the final users or from national and supra-national institutes, and less as an instrument to answer to internal needs and foster internal efficiency. Public servants initiate transformation due to outside pressures, and do not initiate this for solving internal issues or to obtain benefits for their own organization.

\section{Conclusion and Further Research}

Transformation in government to gain the benefits from digitalization is a key issue for most governments. Public Administrations are realizing that ICT cannot be reduced to a mere dematerialization of existing procedures and services, but, on the contrary, it must be combined with a change of the entire organization. Despite a general agreement among scholars on it, no studies quantitatively tested and analyzed the phenomenon so far. This article fills in this gap by conducting a survey in the Netherlands. The results show that ICTs are transforming organizations, and, in particular, they are transforming what the socio-technical theory defines as the technical system of an organization, i.e. processes, employees' duties and tasks, information systems. However, in contrary to the expectations this transformation is not hindered by those barriers that the existing literature identifies as an obstacle to the transformation process. Also transformation is not driven by internal organizational needs. Instead, external pressures towards change are the primary driver of organizational transformation.

Such evidence gives room to several further research avenues. First of all, the study focuses on a single country, characterized by a high maturity in terms of ICT implementation in the public sector. Delivering the same survey to a different country will dive deeper into the phenomenon, understanding if the results can be generalized also in other contexts. Moreover, the counterintuitive evidence of no correlation between the barriers 
and the depth of organizational transformation calls for further analysis to better understand the reasons behind these results. Further studies should design a more complex and comprehensive model, including more elements to better explain the phenomenon.

\section{Appendix I - Questionnaire}

1. From an organizational perspective, so far digitalization in your organization transformed: (1- strongly disagree; 5 - strongly agree):

- Processes (reengineering of the existing processes, process management and control)

- People (duties, tasks, complexity of work, competences)

- Culture (endorsed values, personal and collective behavior)

- Structure (standardization, centralization/decentralization, hierarchy, external relationships, flexibility)

- Information Systems (IS) (introduction of new IS, replacing of the existing ones, integration amongst different IS, interoperability, IT infrastructure)

2. In your organization, the organizational transformation process that goes along with digitalization is hindered by: (1- strongly disagree; 5 - strongly agree)

- Lack of available skills

- Shortage of personnel

- Lack of political support

- Lack of managerial support

- Organizational complexity

- Lack of coordination among the departments/areas of the organization

- Resistance to change

- Bureaucratic culture

- Fear of innovation

3. In your organization the organizational transformation process that goes along with digitalization is pushed by: (1- strongly disagree; 5 - strongly agree)

- Strength of internal leadership

- Internal dissatisfaction about the status quo

- Expected benefits for the administration

- Expected benefits for external actors (stakeholders and/or final users)

- External pressure

- External legal obligations

4. Public Administration:

- Ministry

- Administrative Organization 
- Regional Administration

- Municipality

- Other government

- Private company

- Other (specify).

5. Number of employees of the Administration:

$$
\begin{aligned}
& -\quad \leq 20 \\
& -\quad 21-100 \\
& -\quad 101-400 \\
& -401-2000 \\
& ->2000
\end{aligned}
$$

6. Role:

- Politician

- Director

- Pubic Manager

- Public Servant

- Other (specify)

7. Years of experience in the public sector:

- Less than 5 years

- More than 5 years

8. Years of work in the current organization:

- Less than 2 years

- More than 2 years

\section{Appendix II - Reliability Test}

\begin{tabular}{l|l|l}
\hline & N. of item & Cronbach's alpha \\
\hline OT_TOT & 5 & 0,866 \\
\hline $\begin{array}{l}\text { OT_Tecnical } \\
\text { System }\end{array}$ & 3 & 0,840 \\
\hline SB_TOT & 6 & 0,646 \\
\hline CB_TOT & 3 & 0,668 \\
\hline ED_TOT & 3 & 0,674 \\
\hline ID_TOT & 3 & 0,536 \\
\hline
\end{tabular}


Note. ID_TOT was excluded from the regression analysis due to the low Cronbach's alpha. Cronbach's alpha higher than 0.6 was considered acceptable, due to the exploratory nature of the study

\section{References}

1. Margetts, H., Dunleavy, P.: The second wave of digital-era governance: a quasi-paradigm for government on the web. Philos. Trans. R. Soc. A Math. Phys. Eng. Sci. 371(1987), 1-17 (2013)

2. Dunleavy, P., Margetts, H., Bastow, S., Tinkler, J.: New public management is dead - long live digital-era governance. J. Public Adm. Res. Theor. 16(3), 467-494 (2006)

3. Nograšek, J., Vintar, M.: E-government and organisational transformation of government: black box revisited? Gov. Inf. Q. 31(1), 108-118 (2014)

4. Fountain, J.E.: Public sector: early stage of a deep transformation. In: Litan, R., Rivlin, A. (eds.) The Economic Payoff from the Internet Revolution, pp. 235-268. Brookings Institution Press, Washington, D.C. (2001)

5. Hughes, O.: Public Management And Administration: An Introduction. MacMillan Education (2018)

6. Yildiz, M.: E-government research: reviewing the literature, limitations, and ways forward. Gov. Inf. Q. 24(3), 646-665 (2007)

7. Pollitt, C.: Advanced Introduction To Public Management and Administration. Edward Elgar, Cheltenham (2016)

8. Weerakkody, V., Dhillon, G.: Moving from e-government to t-government: a study of process reengineering challenges in a UK local authority context. Int. J. Electron. Gov. Res. 4(4), 1-16 (2008)

9. Pedersen, K.: E-government transformations: challenges and strategies. Transform. Gov. People Process Policy 12(1), 84-109 (2018)

10. Weerakkody, V., El-Haddadeh, R., Sabol, T., Ghoneim, A., Dzupka, P.: E-government implementation strategies in developed and transition economies: a comparative study. Int. J. Inf. Manage. 32(1), 66-74 (2012)

11. Coursey, D., Norris, D.F.: Models of e-government: Are they correct? an empirical assessment. Public Adm. Rev. 68(3), 523-536 (2008)

12. Moon, M.J.: The evolution of e-government amoung municipalities: rhetoric or reality? Public Adm. Rev. 62(4), 424-433 (2002)

13. van Veenstra, A.F., Klievink, B., Janssen, M.: Barriers and impediments to transformational government: insights from literature and practice. Electron. Gov. Int. J. 8(2/3), 226-241 (2011)

14. Bostrom, R.P., Heinen, J.S.: MIS problems and failures: a socio- technical perspective. MIS Q. 1(3), 17-32 (1977)

15. Al-Emadi, A., Anouze, A.L.: Grounded theory analysis of successful implementation of egovernment projects: exploring perceptions of e-government authorities. Int. J. Electron. Gov. Res. 14(1), 23-52 (2018)

16. Weerakkody, V., El-Haddadeh, R., Sivarajah, U., Omar, A., Molnar, A.: A case analysis of e-government service delivery through a service chain dimension. Int. J. Inf. Manage. 47, 233-238 (2019)

17. Gascó, M.: New technologies and institutional change in public administration. Soc. Sci. Comput. Rev. 21(1), 6-14 (2003)

18. Ashaye, O.R., Irani, Z.: The role of stakeholders in the effective use of e-government resources in public services. Int. J. Inf. Manage. 49, 253-270 (2019) 
19. Ebrahim, Z., Irani, Z.: E-government adoption: architecture and barriers. Bus. Process Manag. J. 11(5), 589-611 (2005)

20. Wirtz, B.W., Langer, P.F.: Public multichannel management - an integrated framework of offand online multichannel government services. Public Organ. Rev. 17(4), 563-580 (2017)

21. Eynon, R., Dutton, W.H.: Barriers to networked governments: evidence from Europe. Prometheus 25(3), 225-242 (2007)

22. Janssen, M., Cresswell, A.M.: An enterprise application integration methodology for e-government. J. Enterp. Inf. Manag. 18(5), 531-547 (2005)

23. Meijer, A.J.: E-governance innovation: barriers and strategies. Gov. Inf. Q. 32(2), 198-206 (2015)

24. Mohammad, K.: E-leadership: the emerging new leadership for the virtual organization. J. Manag. Sci. 3(1), 1-21 (2009)

25. Mergel, I., Edelmann, N., Haug, N.: Defining digital transformation: results from expert interviews. Gov. Inf. Q. 36(4), 1-16 (2019)

26. European Commission, eGovernment Benchmark 2019: trust in government is increasingly important for people (2019)

27. Williamson, Ó.: Transaction cost economics: how it works; where it is headed. Entomol. Exp. Appl. 146, 23-58 (1998) 